Anales de Literatura Hispanoamericana

ISSN-e: 1988-2351

\title{
Un relato sobre la trata de mujeres
}

\begin{abstract}
Alice Favaro ${ }^{1}$
Resumen. Beya. Le viste la cara a Dios, es la transposición en historieta de la novela breve Le viste la cara a Dios. La bella durmiente. Publicada en 2011, la historieta aborda el tema sumamente actual de la trata de mujeres en Argentina que la autora, propone una reescritura de La Bella Durmiente. La protagonista, Beya, es una joven víctima de las redes de prostitución en el conurbano bonaerense que, después del secuestro, está obligada a prostituirse y vivir en cautiverio. La novela gráfica narra la historia de la protagonista con imágenes violentas que se mezclan con un registro lingüístico vulgar. Los dos lenguajes se cruzan para narrar, desde el punto de vista de las víctimas, la tragedía de la desaparición de mujeres en manos de las redes de prostitución. El texto fuente y el hipertexto representan un instrumento de denuncia social y colocan al lector ante una evidente violación de los derechos humanos.
\end{abstract}

Palabras clave: Transposición; literatura; historieta; violencia; trata de mujeres.

\section{[en] A story about trafficking in women}

\begin{abstract}
Beya. Le viste la cara a Dios, is the comic transposition of the short novel Le viste la cara a Dios. La bella durmiente. Published in 2011, the comic book deals with the highly topical issue of trafficking in women in Argentina, which the author proposes a rewriting of Sleeping Beauty. The main character, Beya, is a young victim of prostitution networks in the Buenos Aires suburbs who, after being kidnapped, is forced to prostitute herself and live in captivity. The graphic novel tells the story of the protagonist with violent images mixed with a vulgar linguistic register. The two languages intersect to narrate, from the victims' point of view, the tragedy of the disappearance of women in the hands of prostitution networks. The source text and the hypertext represent an instrument of social denunciation and place the reader in front of an obvious violation of human rights.
\end{abstract}

Keywords: Transposition; literature; comic strip; violence; trafficking in women.

Cómo citar: Favaro, A. (2020) Un relato sobre la trata de mujeres, en Anales de Literatua Hispanoamericana 49, $287-293$.

Concentrar la atención sobre el sujeto subalterno y el margen permite a la narrativa argentina contemporánea novelar, a través de la ficción, los males que afligen la realidad social, política y cultural del país hoy en día. Muchas de las novelas que se incluyen en el ámbito de la literatura argentina contemporánea presentan algunos elementos comunes y reiterados en que se reconoce la presencia de personajes siniestros que viven en los márgenes de la sociedad, que se mueven por suburbios y periferias urbanas -donde se representa la vida cotidiana en los barrios más inquietantes de la capital-, empleando un registro lingüístico coloquial y directo, y a veces aparece, inesperadamente, lo fantástico. Los estudios más recientes y exhaustivos sobre este tipo de literatura son los trabajos de Elsa Drucaroff, quien ofrece una definición de "Nueva Narrativa Argentina" en su ensayo Los prisioneros de la torre. Política, relatos y jóvenes en la postdictadura (2011), y Beatriz Sarlo, que analiza treinta y tres obras de autores argentinos a los que considera integrantes de la "literatura del presente" en Ficciones argentinas. 33 ensayos (2012). Aunque se trata de los únicos puntos de referencia teóricos sobre la narrativa argentina contemporánea, las dos obras no permiten identificar un verdadero canon y dan cuenta de una situación y un proceso todavía in fieri. Sin embargo, se nota una tendencia predominante en la predilección de los autores, de lo que Sarlo define "realismo etnográfico" (Sarlo 2006), es decir la representación documental de la realidad en la ficción, y de lo que Piglia definía como "el desplazamiento, la distancia" (Piglia 2009), el salir del centro y dejar hablar al otro, desde el borde. 
En este marco se sitúa Le viste la cara a Dios. La bella durmiente (2011) de Gabriela Cabezón Cámara. La novela breve forma parte de un proyecto de la editorial Sigueleyendo que en 2010 pidió a varios escritores latinoamericanos que se encargasen de reescribir un cuento clásico de la literatura para editarlo en formato digital. La propuesta de Cabezón Cámara fue la reescritura de La Bella durmiente en tres editoriales, formatos y soportes diferentes: ebook, libro y novela gráfica. La autora, nacida en 1968 en Buenos Aires, en la actualidad responsable de la sección cultural del diario Clarín, debutó en el circuito editorial argentino con La Virgen Cabeza (2008) publicado por Eterna Cadencia.

La novela propone la relectura del cuento clásico de la Bella Durmiente abordando el tema de la trata de mujeres en Argentina. Beya, la protagonista es una joven víctima de las redes de prostitución en el conurbano bonaerense que, después del secuestro, está obligada a prostituirse y vivir en cautiverio en un burdel de Lanús. El cuento de hadas de la tradición oral europea al cual se hace referencia, La bella durmiente del bosque, cuenta con numerosas versiones. Las más conocidas son la de Charles Perrault contenida en Los cuentos de Mamá Ganso (1697) y la de los Hermanos Grimm "Rosita de Espino" o "La bella durmiente del bosque", publicadas en Cuentos de la Infancia y el Hogar (1812), que utilizaron una versión similar a la de Perrault. Las versiones más antiguas son El Roman de Perceforest, texto literario francés anónimo compuesto hacia 1340, y "Talía, Sol y Luna”, de Giambattista Basile (Pentamerón, 1634). En la primera versión Basile aludía a un estupro, Perrault, en cambio, evitó los detalles perturbadores para adaptarlo a un público altoburgués. También Italo Calvino, en Cuentos populares italianos (Fiabe italiane raccolte dalla tradizione popolare durante gli ultimi cento anni e trascritte in lingua dai vari dialetti, 1956), propuso una versión de "La bella durmiente y sus hijos" procedente de la región de Calabria. En el relato, similar a la versión propuesta por Basile, el autor imputa la causa del embarazo a una violación; se cuenta la historia de la bella durmiente que queda embarazada de dos gemelos, llamados Sol y Luna precisamente como en el relato del Basile, por el amor que el hombre siente por ella. Según la interpretación psicoanalítica de La bella durmiente del bosque, de Bruno Bettelheim, el largo período de sueño de la princesa sería el período que precede y sucede la llegada de la primera menstruación en las adolescentes, un tiempo en que las jóvenes mujeres aparecen como pasivas y adormiladas. El despertar correspondería a la necesidad de aceptarse a sí mismas y encarar al mundo. Por mucho que los padres intenten impedir el florecimiento sexual de sus hijas, este se producirá de manera implacable y en el momento en que la niña alcanza la madurez física y emotiva, está lista para el amor. La moraleja del cuento sería lo innecesario de forzar las situaciones pues, llegado el momento adecuado, se encuentra solución a los problemas.

Los autores posmodernos que han reescrito este clásico son numerosos. En España, por ejemplo, destaca la catalana Ana María Matute con El verdadero final de la Bella Durmiente (1995) que ofrece un final diferente del relato en que la princesa se encuentra atrapada en una realidad que se demuestra distinta de la que parecía, sometida a la voluntad del príncipe y en un estado de pasividad. En Argentina, Luisa Valenzuela también ha reelaborado esta historia pero desde otra perspectiva, haciendo hincapié en la reivindicación del cuerpo (Regazzoni 2010). La escritora ha reescrito la trama de La bella durmiente en algunos relatos contenidos en Simetrias (1993) en la sección "Cuentos de hades". En el breve relato "4 príncipes 4" compuesto por cuatro breves historias de príncipes- en "Príncipe II" el protagonista es un hombre que besa a todas las mujeres que encuentra despertándolas con su beso, a la espera de su princesa; cuando, por fín, encuentra a la bella princesa durmiente, la que sabe ser la mujer de su vida, no es capaz de besarla de tan hermosa y tan perfecta que es y se revela un inepto. En cambio en "No se detiene el progreso", que se basa en La bella durmiente sólo en mínima parte, Valenzuela cuenta la historia de una princesa que se queda dormida y de un príncipe que la despertará, un siglo después, pero al final del relato es la princesa quien atrapa al príncipe porque de sus brazos crecen unos zarcillos viscosos que lo entrampan.

La obra de Cabezón Cámara que nos interesa ha sido transpuesta a través de dos lenguajes: una adaptación teatral, realizada por Marisa Busker, que se estrenó en febrero 2016 en los teatros de Buenos Aires y una historieta, Beya (Le viste la cara a Dios), con guion de la misma autora y dibujos de Iñaki Echeverría, ilustrador nacido en Balcarce en 1974 que publica tiras en Página/12 y en Fierro.

En ambas obras, el hipotexto y el hipertexto en la historieta, la literatura y el cómic devienen instrumentos de denuncia social y material documental que colocan al lector frente a un caso de negación de los derechos humanos. La novela narra la verdadera historia de Marita Verón (María de los Ángeles Verón), secuestrada el 3 de abril de 2002 en la provincia de Tucumán, desaparecida a la edad de 23 años. El proceso, empezado el 8 de febrero de 2012 en Tucumán con 13 personas imputadas, terminó el 10 de diciembre de 2012 con todos absueltos. Al presentar la apelación por parte de los abogados de la familia Verón, la Corte Suprema Tucumana fue a favor de la familia Verón, señalando a los imputados como culpables. Aunque todos los condenados tuvieron que esperar la sentencia en firme, cumpliendo prisión preventiva, fueron liberados hasta que la sentencia quedara firme. El viernes 4 de noviembre de 2016 la Corte Suprema de 
Tucumán publicó su rechazo a la apelación de los imputados, por lo que los abogados de la familia Verón pidieron inmediatamente la prisión de todos los condenados. ${ }^{2}$

La narración se desenvuelve entre diferentes ambientaciones pertenecientes a las orillas suburbanas donde se reivindican los derechos de los cuerpos de las víctimas en contra de quienes los torturan, violan, reprimen, destruyen. El títiulo, Le viste la cara a Dios, La bella durmiente en el hipotexto, se transforma en la transposición en cómic en Beya (Le viste la cara a Dios), y da cuenta de la metamorfosis que sufre la mujer. Beya es el "nuevo" nombre que le dan a la protagonista en su vida prostibularia. En la trasposición, el título modificado propone un juego lingüístico dado por el mismo sonido de las letras "ll" -“y”, cuyo empleo transfigura la palabra "bella" y transforma el adjetivo en sustantivo-. La protagonista ya no es la Bella durmiente sino que es simplemente Beya, como si también su belleza hubiese sufrido una metamorfosis. Ya en el título, pues, la transposición ofrece una versión del hipotexto modificado y asumido desde una perspectiva diferente en que la oralidad se impone en la norma lingüística y genera la nueva identidad de la protagonista.

El uso de frases breves en el texto fuente, con un realismo exasperado que describe lo más vulgar y bajo, acentúa el lenguaje violento y el ritmo vertiginoso del relato. El texto construye un cuento hipnótico a partir de una modulación rítmica repetitiva, casi con el ritmo del rap, con versos cortos y un léxico que evoca imágenes continuamente, casi pornográfico, adoptando una estrategia narrativa extremamente visual. La narración de la metamorfosis que sufre la protagonista acontece y se desarrolla en paralelo: por una parte la joven se convierte en una prostituta y aprende el oficio y por el otro entiende que le conviene aparecer sumisa y obediente mientras prepara su venganza. Empieza así a delinearse en el texto, después de un denso momento inicial en que el lector sigue el sufrimiento y la humillación de la protagonista en su vida diaria en cautiverio, la necesidad de la víctima de redimirse desde el lado más oscuro de la marginalidad, de la violencia, de la locura, convirtiéndose en una heroína. La represión de los derechos del individuo en la esclavitud sexual se manifiesta a través del lenguaje en la expresión "cosecha de mujeres" (11) que hace referencia al ambiente rural. Los personajes, que no tienen voz propia, aparecen como si fueran mudos o costreñidos al silencio y hablan a través de sus acciones. De hecho, como en la historieta, no son los diálogos los que explican lo que acontece, el estado de ánimo y los pensamientos de la protagonista, sino el texto de las acotaciones.

Las numerosas referencias, a lo largo de la narración a la religión y a las creencias populares a través de la literatura y el arte, destacan las conexiones entre lo sagrado, la muerte y el sexo. La religiosidad presente en la narración, exasperada y blasfema, se representa por medio de escenas religiosas que son citas o referencias a pinturas famosas. Hay un paralelismo entre el sufrimiento de la protagonista, que encuentra en la fe un refugio y reza para que su alma sea absuelta de los pecados, y el sufrimiento de Cristo. El hecho de encontrar amparo en la religión produce en la protagonista un efecto de bilocación y desdoblamiento, en que el alma se separa del cuerpo, representando una manera para huir de la realidad demasiado atroz, como se lee en el texto: "querés fuga y bilocación, un espíritu que sepa estar en otro lugar, muy lejos mas sin morirte, vos querés desdoblamiento cual místico en viaje astral y cantar como San Juan la noche oscura del alma" (Cabezón Cámara 2011: 7). En la historieta, que dramatiza este aspecto, la protagonista está dibujada como en un díptico, al lado de la Virgen, adornada por una guirnalda de falos en lugar de una guirnalda de flores o representada crucificada y ornada con capullos de flores que parecen úteros. La narración avanza, en una continua intersección entre lo culto y lo popular, lo sagrado y lo profano, que da cuenta de la degradación de Beya con un lenguaje descarnado y cargado de violencia al mismo tiempo.

La perspectiva del narrador, focalizada desde la subjetividad de la protagonista, se mezcla con la segunda persona que se acerca a la oralidad y que registra las distintas etapas de la trata, invoca la mujer a actuar y la exhorta a cultivar el odio. Las numerosas experiencias de viaje fuera del cuerpo de la protagonista evocan los testimonios contados por las víctimas secuestradas durante la dictadura militar mientras eran torturadas. En este estado de enajenación física se narran, sin omitir los detalles más violentos, el tormento, el delirio místico, la gestación imaginaria del odio, la sed de venganza, la recuperación: "[...] lo que podés es cuidar a tu odio como si fuera un bebé recién nacido [...] el monstruito está hecho de todo lo que te duele y cuando llegue a su término la asquerosa gestación, te van a nacer diez púas en las puntas de los dedos" (Cabezón Cámara 2011: 13). Una vez más la historieta hace hincapié en este aspecto, dibujando a la mujer con una 
especie de monstruo en el vientre y ornándola con un enredo de espinas, que recuerda la pasión de Cristo, y con unas flores que parecen úteros.

La violencia se manifiesta en el cuento, además, a través de la dicotomía entre civilización -la ciudad- y barbarie -el burdel de Lanús. Es inmediata la referencia a El matadero de Echeverría, al que se alude directamente en la primera estrofa, mediante la comparación del cuerpo de la joven con el cuerpo de la vaca: "Si a Matasiete el matambre, a vos el resbalar en tu sangre" (Cabezón Cámara 2011: 6), estrofa que detiene en los roles de torturador y víctima. De hecho la misma escritora confirmó, en una entrevista, que para ella existe un imaginario nacional de escritura de la violencia al que no puede renunciar y que ya casi no puede pensar la violencia sin referirla a algunos textos literarios (Domínguez 2014a: 2).

La representación del mundo de las orillas suburbanas, desde lo más oscuro de la marginalidad, relata una entre las tantas trágicas historias de mujeres quebradas, víctimas de la violencia masculina. Cuerpo y voz en la novela se separan y la narración se proyecta desde un "vos" que crea un dúplice efecto: en algunos puntos el empleo de la segunda persona singular parece la voz de Beya que le habla directamente al lector y, en otros, la narradora que se dirige a la protagonista. El uso de la segunda persona enfatiza, pues, el desdoblamiento de Beya frente al dolor, que se aparta de la primera persona y se convierte en una tercera, y esta voz violenta e imperativa construye otra salida para la narración. La mezcla de registros lingüísticos entre oral/bajo y culto/con referencias literarias y culturales da lugar a una suerte de fábula de redención en que se vuelca el mito femenino congelado en la belleza. El final inesperado, -la mujer se hace justicia a sí misma y pasa de víctima a vengadora-, se distancia de lo que realmente acontece a las víctimas -o sea la desaparición o la muerte- y puede interpretarse como un grito de esperanza.

El cuerpo femenino capturado se convierte, en la novela, en un cuerpo de ficción y el secuestro con que inicia el relato hace claramente referencia a la última dictadura militar, como se puede leer en una entrevista hecha a la autora: "[...] el relato exige atravesar el guión del secuestro y de esta manera pasa a emparentarse con los relatos de secuestros y torturas de la dictadura y en segundo lugar, lo obliga a emplazarse en las lógicas prostibulares y aquí es donde podemos distinguir una larga tradición en la novela argentina y establecer otros vínculos" (Domínguez 2014: 5). La protagonista llega a un punto extremo en términos de sometimiento y experiencias físicas límite donde el cuerpo-mercancía se convierte en espacio de resistencia. El cuerpo de la mujer, que como escribe Domínguez "es decididamente un territorio de imaginación biopolítica [...] exiliado de su vida por el delito de la trata de personas, enajenado por la explotación sexual y el terror desatado en el puti-club, llevado a la extenuación de sus funciones vitales y subjetivas" (Domínguez 2014b: 23), es aquí un disparador narrativo en que la literatura es el instrumento de denuncia sobre un problema actual. Es un cuerpo desnudo, abandonado en la soledad del cautiverio, acurrucado, en que la mujer se cubre el rostro con los brazos, se encierra en sí misma hasta desaparecer. Un "cuerpo amatambrado" (Dominguez 2014b: 25) que asume el papel principal en que lo más abyecto estalla, llevado a la aniquilación, al extremo, donde se retrata la corporalidad en su parte más animal y baja. En una continua mezcla entre moderno y posmoderno, al referirse a los estilos artísticos y a diferentes períodos de la historia nacional y de la violencia política, el texto es sumamente actual no solo por el tema tratado sino también por su estilo y lenguaje.

Su transposición en historieta, primera novela gráfica del catálogo editorial de Eterna Cadencia, publicada en 2013, representa un caso original ya que la autora del texto fuente se autotraspone y es también la guionista de la transposición en cómic. La novela gráfica recibió el premio Alfredo Palacios, otorgado por el Senado de la Nación, por su contribución a la lucha contra la trata de personas y fue declarada de interés social y cultural por la Legislatura de la Ciudad de Buenos Aires. Además, recibió el Premio del Lector como mejor libro del año durante la Feria del Libro de Buenos Aires en 2014. La obra, que no se puede definir una verdadera transposición en historieta, es una novela gráfica o versión ilustrada de la novela porque casi no hay globos y prevalecen las imágenes con las acotaciones; se podría situar a caballo entre el poema ilustrado y la graphic novel en la que el texto no se encuentra dentro de la viñeta sino al lado. En la transposición, que al principio de la historieta añade el epígrafe: "Aparición con vida de todas las mujeres y nenas desaparecidas en redes de prostitución. Juicio y castigo a los culpables" sitúa al texto en una doble referencia: por una parte la verdadera historia de Marita Verón, y los frecuentes casos en Argentina de trata de mujeres; por el otro la referencia a la última dictadura militar. De hecho, en la narración se intersecan el campo de concentración con el prostíbulo. Dividida en cinco partes, la novela gráfica, hace particular hincapié en la reivindicación del cuerpo femenino - que ya en la primera imagen está representado como si fuera un objeto en venta con código de barras en el fondo-, la afirmación de sus derechos, la violencia, las conexiones con lo sagrado y la transmedialidad. A través de la manera en que se narran los cuerpos atravesados por la violencia, "el formato del cómic soporta los silencios de un cuerpo robado y ultrajado que interpela al lector exigiendo juicio y castigo a los responsables de la trata de personas" (Ríos, 1). La 
historieta exacerba lo trágico de la historia contada donde el cuerpo dominado física y moralmente por el otro-hombre es un cuerpo que está secuestrado y prostituido justo por ser un cuerpo femenino ${ }^{3}$. En el espacio del prostíbulo, un espacio imaginario poblado por vidas aniquiladas en tránsito y en trampa, la potencia del lenguaje y del estilo narrativo de Cabezón Cámara se fusiona con las imágenes explícitas de Echeverría. El resultado es una novela gráfica con un estilo agresivo que atrae al lector de principio a fin en una única lectura, bajo una atmósfera de terror y horror que nos acerca, aún más, al sufrimiento de la víctima y al deseo de hacer justicia ${ }^{4}$.

Las imágenes cruentas en las descripciones de los abusos sufridos por la protagonista transmiten al lector el sentido de pérdida de la dignidad y de la posesión sobre el propio cuerpo que paulatinamente percibe la protagonista mientras es violada por sus clientes habituales, entre los cuales destacan policías, jueces, curas y políticos. Las imágenes se mezclan con un registro lingüístico bajo y vulgar, un vocabulario prostibulario, donde hipotexto e hipertexto dialogan continuamente. Los lenguajes visual y verbal se compenetran para narrar la tragedia de la desaparición de las mujeres desde el punto de vista de las víctimas, enfatizado por el empleo del "vos" con el que la narradora se dirige al lector para aumentar la cercanía a la narración. Beya, representada siempre desnuda, aparece primero desfigurada por los efectos de las drogas que constantemente le suministran y después, utilizando el estilo del fileteado típico del ambiente tanguero, como si fuera una vaca, esperando a ser descuartizada antes de llegar a la carnicería. En la historieta se lee: "[...] como no se acaba nunca la cosecha de mujeres y eso te lo hacen saber, no te vayas a olvidar, que ellos te pueden pasar a degüello como a un chancho y filetearte después como si fueras jamón" (Cabezón Cámara 2011: 11). El paralelismo entre mujer y bestia está enfatizado en diferentes partes del texto, por ejemplo en la frase: “[...] como a una marioneta [...] no te mata porque sos su hacienda y le rendís viva, le rinde tu kilo en pie o mejor dicho en cuatro patas (Cabezón Cámara 2011: 9) y en el hipertexto en el pasaje: "ya lo dice el cuervo rata:/ «Mis putas me rinden más/ que las vaquitas al Farmer/ más poronga de mis clientes»" (Cabezón Cámara, Echeverría 2013: 36), donde la mujer se convierte en mera carne para ser fuente de placer y de ganancia.
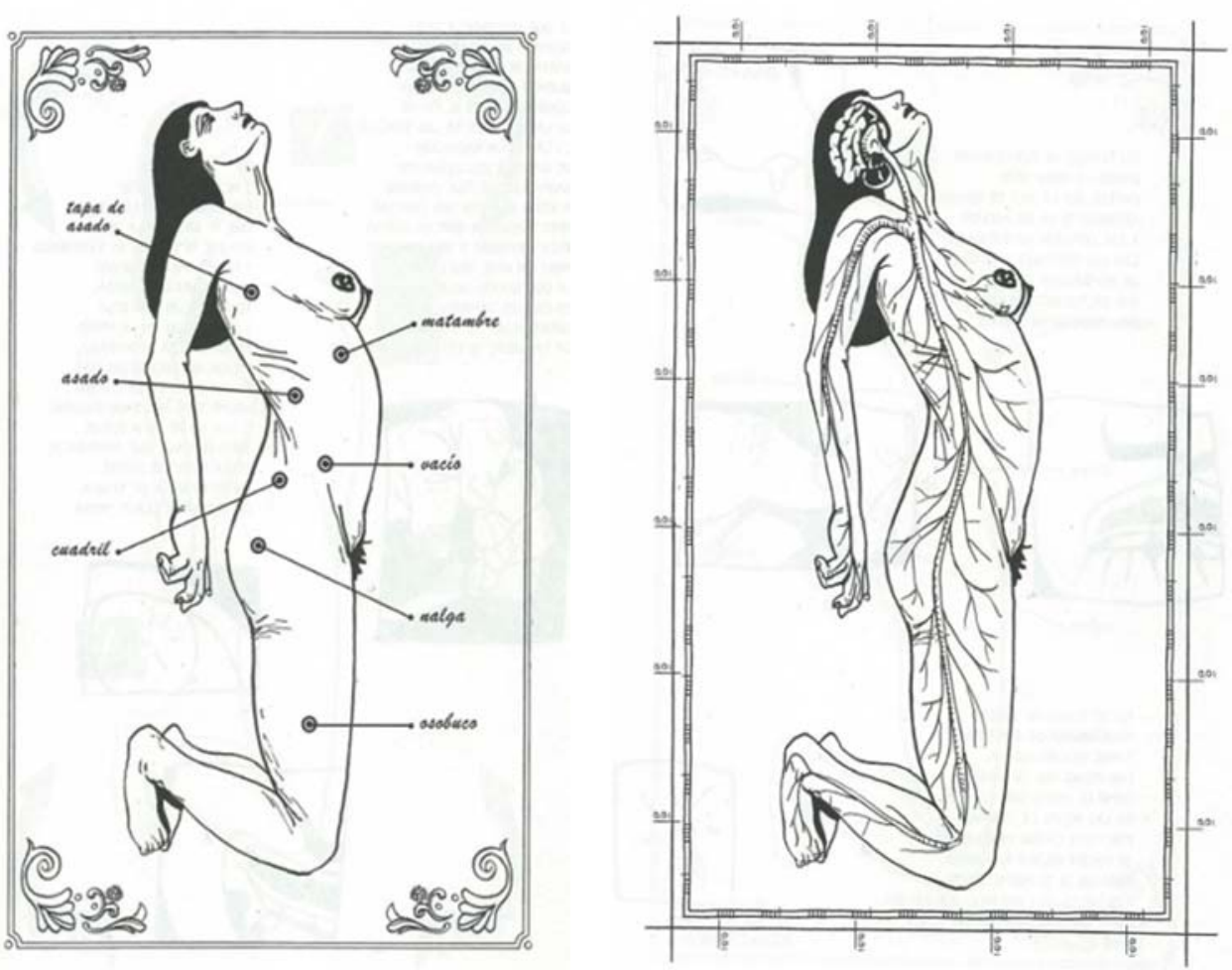

La descomposición de las viñetas rectangulares procede, a medida que avanza el secuestro, paralela a la descomposición y deshumanización que está sufriendo a nivel psicológico y físico la protagonista. El zoom 
en los detalles, en un cambio continuo de planos, en que se multiplican los puntos de vista y la lejanía conseguida gracias a los enfoques desde arriba en diferentes momentos de la narración enfatiza el efecto de desdoblamiento que siente la joven. En la composición de la página la lógica habitual de las viñetas está invertida ya que están desparramadas en la hoja. Las partes blancas subrayan un diferente ritmo de la narración y representan el martirio de la esclavitud sexual que induce a la "Beya durmiente" a fingirse inconsciente, a perderse o desdoblarse mentalmente para resistir a la violencia, al "ablande" al cual está sometida. Las secuencias fragmentarias están intercaladas con imágenes a página entera en las que están presentes alusiones a la iconografía cristiana donde se refugia la protagonista.

La acertada elección de insertar el texto solo después de las quince páginas iniciales del primer capítulo y adyacente a los dibujos que lo ilustran, denota la voluntad de dejarlo en una posición de subordinación con respecto a la imagen donde el silencio imprime un tono de suspenso a la narración. El choque entre el lenguaje culto y el lenguaje vulgar, empleando expresiones típicas del habla porteña, se mezcla con las escenas de las torturas y violaciones alternadas a las referencias a las pinturas notorias. El ritmo del cuento se escande con la alternancia del blanco y el negro cuyas palabras disparan imágenes y la voz en off de la narradora propone la venganza y se accede a diferentes niveles de lectura, como afirma Domínguez: "se entrelazan dos partes de la novela, la que narra el exceso de la opresión, escalvización, pornografía y muerte con la del desdeo de vida y la potencia femenina" (Domínguez, 2013: 143).

La yuxtaposición de dimensiones diferentes, y distintos momentos de la historia cultural, permite la continua mezcla entre lo popular, lo erudito y la experiencia religiosa -que aparece como posibilidad de salvación-, que se manifiesta a través de la transmedialidad y la intertextualidad. De hecho las referencias a pinturas notorias, reinterpretadas en formato cómic y con un lenguaje contemporáneo, son evidentes y a lo largo de la historieta es posible reconocer la Adoración de los pastores (1612-1614) de El Greco o La trasfiguración (1518-1520) de Rafel, donde se nota en la parte inferior izquierda una referencia a un detalle de El Juicio Final (1535-1541) de Miguel Ángel, y La última cena (1495-1498) de Leonardo da Vinci. Las pinturas mezcladas períodos históricos y corrientes artísticas diferentes y se entrecruzan arte moderno y contemporáneo, como la referencia a El beso (1907-1908) y a Maternidad. Las tres edades de la mujer (1905) o Eperanza II. Visión, fecundidad, leyenda (1907-1908) de Klimt. Además de las alusiones literarias y artísticas, la historieta añade la referencia al cine en que Beya está paragonada a la protagonista de Kill Bill, sedienta de venganza.

Las dos obras, singulares no solo porque la transposición en historieta ha permitido una mayor circulación y visibilidad a la novela a través de la publicación con una editorial como Eterna Cadencia, sino también porque la autora es guionista de sí misma, representan un caso original que trata un tema sobre el que, hasta el momento, se ha escrito muy poco en forma de ficción. La novela podría formar parte de aquel "realismo etnográfico" explicado por Sarlo y la historieta podría leerse como graphic journalism o cómic reportaje/reportaje con viñetas, recientemente muy difundido. Se trata de una manera rápida y eficaz para llegar a un amplio público, ofreciendo un cuadro general de la situación de la que se quiere hablar y empleando el cómic para sensibilizar a la sociedad. De hecho las contradicciones sociales y los fenómenos migratorios que se explicitan a través de conflictos, inmigración, desigualdad son temas que denotan la profunda crisis del hombre contemporáneo y que encuentran en el periodismo gráfico y en el "realismo etnográfico" los medios privilegiados de expresión.

\section{Referencias bibliográficas}

Bettelheim, Bruno (1994). Psicoanálisis de los cuentos de hadas. Barcelona: Crítica.

Cabezón Cámara, Gabriela (2011). Le viste la cara a Dios. La bella durmiente. Barcelona: Sigueleyendo.

Cabezón Cámara, Gabriela y Echeverría, Iñaki (2013). Beya. Le viste la cara a Dios. Buenos Aires: Eterna Cadencia.

Calvino, Italo (1956), "La bella addormentata e i suoi figli", en Fiabe italiane raccolte dalla tradizione popolare durante gli ultimi cento anni e trascritte in lingua dai vari dialetti da Italo Calvino. Turín: Einaudi.

Domínguez, Nora (2013), "Movimientos ficcionales y no ficcionales de la violencia. Crímenes de mujeres", Aletria. Revista de Estudos de Literatura, $\mathrm{n}^{\circ}$ 1, enero-abril, Belo Horizonte.

Domínguez, Nora (2014a), "Conversaciones y reenvíos con Gabriela Cabezón Cámara”, Cuadernos LIRICO. Revista de la red interuniversitaria de estudios sobre las literaturas rioplatenses contemporáneas en Francia, no 10, pp. 1-6.

Domínguez, Nora (2014b), "La trilogía de Gabriela Cabezón Cámara: entre el enclave formal y la sedición de los cuerpos", en Marta Palchevich y Ana Laura Rivara (eds.). Literatura y política. Boletín de la BCN, $\mathrm{n}^{\circ}$ 128, Buenos Aires: Biblioteca del Congreso de la Nación, pp. 23-29.

Drucaroff, Elsa (2011). Los prisioneros de la torre. Política, relatos y jóvenes en la postdictadura. Buenos Aires: Planeta. 
Favaro, Alice (2019), “La «Beya» durmiente. Entre reescritura y transposición”, Cuaderno 71. Artes dibujadas: cartografías y escenas de la Historieta, el Humor Gráfico y la Animación. Cuadernos del Centro de Estudios de Diseño y Comunicación, año 19, nº 74, marzo 2019.

Matute, Ana María (1995). El verdadero final de la Bella Durmiente. Destino: Barcelona.

Piglia, Ricardo (2009), "Tres propuestas para el próximo milenio (y cinco dificultades)", Pasajes. Revista de pensamiento contemporáneo, 28, pp. 81-93.

Regazzoni, Susanna (2010), "Cuando la curiosidad te salva. El Barbazul de Luisa Valenzuela”, en Silvana Serafin, Emilia Perassi, Susanna Regazzoni y Luisa Campuzano (eds.). Más allá del umbral. Autoras hispanoamericanas y el oficio de la escritura. Sevilla: Renacimiento, pp. 213-234.

Ríos, Marina Cecilia (2016), "Vidas soportadas: de la zoé (bios) a la vida ovillada", en IV Coloquio Internacional "Literatura y vida”, 8-10 junio, Rosario.

Sarlo, Beatriz (2006), "Sujetos y tecnologías. La novela después de la historia", Punto de vista, 86 (29), pp. 1-6.

Sarlo, Beatriz (2012). Ficciones argentinas. 33 ensayos. Buenos Aires: Mardulce.

Valenzuela, Luisa (1996)[1993]. Simetrías. Barcelona: Plaza \& Janes.

“El caso Marita Verón”, http://casoveron.org.ar/ 